\title{
Temporal changes in state of stress in the Tokachi Oki area after the 2003 Tokachi Oki Earthquake
}

\author{
Subesh Ghimire, Kei Katsumata, and Minoru Kasahara \\ Institute of Seismology and Volcanology, Hokkaido University, Japan \\ (Received June 28, 2004; Revised February 7, 2005; Accepted February 10, 2005)
}

\begin{abstract}
A stress tensor inversion was carried out in the aftershock area of the 2003 Tokachi Oki earthquake for a comparative study on the preseismic and postseismic stress state. The inversion technique was adopted from Gephart (1990) to pursue the study with earthquake focal mechanism data from National Research Institute for Earth Science and Disaster Prevention (NIED). Results of the inversion revealed significant change in stress field before and after the main shock of the 2003 event. The preseismic uniaxial compression in strike slip stress regime was changed to a transition from transpressional to a radial compression in a compressional regime.
\end{abstract}

Key words: 2003 Tokachi Oki earthquake, stress tensor inversion.

\section{Introduction}

The Hokkaido Island, at the northern extreme of Japanese arc, is situated at the arc-arc collision zone accompanied by the southwestward migration of the Kuril Arc during the late Miocene (Seno, 1985; Moriya, 1986; DeMets, 1992; Tsumura et al., 1999). Tectonics of Hokkaido and its suburbs is further complicated by the consumption of both the Pacific plate along the Kuril Trench and the Japan Trench (Kanamori, 1971a, Suzuki et al., 1983; Moriya, 1986). In the Tokachi Oki region, the subduction rate of Pacific plate is estimated to $8 \mathrm{~cm} / \mathrm{yr}$ towards NW (DeMets et al., 1990). Therefore, occurrence of great earthquakes along the Kurile trench is very common. However the interplate seismic activities are confined in the vicinity of the Kurile trench, intermediate to deep focus intra-slab earthquakes are frequently occurring in Hokkaido and its outskirts and the mechanism for individual type may vary in time and space (Ozel and Moriya, 1999; Kosuga et al., 1996; Schwartz and Ruff, 1985), where seismicity may reach up to a depth of 600 km (Hasegawa et al., 1983).

As discussed by many previous workers, seismic activity seems to be confined at three distinct depths in this area (e.g. Hasegawa et al., 1978, 1983; Moriya, 1986; Suzuki and Kasahara, 1996; Katsumata et al., 2003). The shallow events $(<40 \mathrm{~km})$ of interplate type are associated with the mechanical coupling and decoupling of the two lithospheric slabs characterized by low angle thrusting. The intermediate depth events $(40-120 \mathrm{~km})$ and deep $(>120 \mathrm{~km})$ events are responsible for or associated with the rupture of downgoing lithospheric slab and are intraslab or intraplate type. Nevertheless, in such kind of tectonic environment, some shallow events characterized by normal faulting may be associated with the intraplate type (Kanamori, 1971b;

Copy right(c) The Society of Geomagnetism and Earth, Planetary and Space Sciences (SGEPSS); The Seismological Society of Japan; The Volcanological Society of Japan; The Geodetic Society of Japan; The Japanese Society for Planetary Sciences; TERRAPUB.
Isacks and Molnar, 1971; Astiz et al., 1988). Like northern Honshu as discussed by Yoshii (1979), seismic activities in this region has imaged a double seismic zone (Suzuki et al., 1983) whereas Moriya (1986) insisted the double seismic zone as an apparent image of the two lithospheric slabs overlapped due to contortion, or even plastic deformation of the Pacific Plate subducting in this region.

As a regular seismic phenomenon in this tectonic province, the great earthquake of Tokachi Oki occurred on Sep. 26, 2003 at 04:50 am (JST). The National Research Institute for Earth Science and Disaster Prevention (NIED, http://www.bosai.go.jp), Japan, measured this earthquake with magnitude (Mw) 7.9 at $22 \mathrm{~km}$ depth at latitude 41.7 and longitude 144.2 (Fig. 1). The main shock of Tokachi Oki earthquake was followed by enormous aftershock sequence.

The purpose of this study is to evaluate the change in state of stress in the Tokachi Oki area after the great earthquake of 2003 so as to constrain some important insights on earthquake phenomenology in terms of temporal change in stress state. For this purpose a method propounded by Gephart and Forsyth (1984) was employed.

\section{Stress Tensor Inversion}

There are many methods of stress tensor inversion that use focal mechanism data (e.g. Gephart and Forsyth, 1984; Michael, 1984, 1987; Carey-Gailhardis and Mercier, 1987). All these inversion techniques hypothesize two basic assumptions: (a) the deviatoric stress tensor in the area under study is homogeneous and (b) slip occurs along the direction of the maximum shear stress resolved.

The method of Gephart and Forsyth (1984) is extensively used in various tectonic provinces to evaluate the states of stress (e.g. Gephart and Forsyth, 1984; Magee and Zoback 1993; Frepoli and Amato, 2000; Kiratzi, 2002; Kubo and Fukoyama, 2003). This method of stress inversion was selected for this study.

The inversion calculates four unknown parameters defin- 


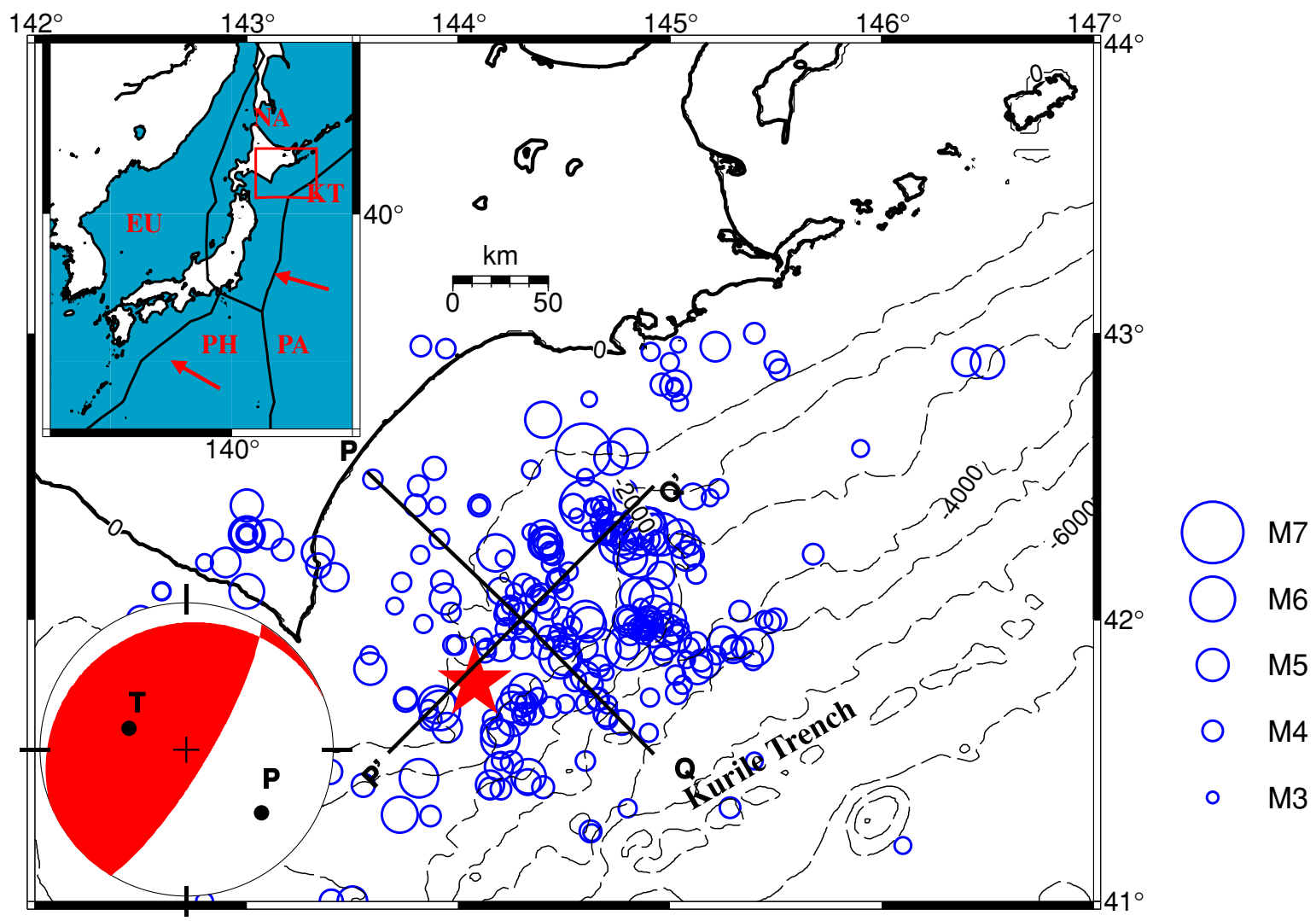

(a)

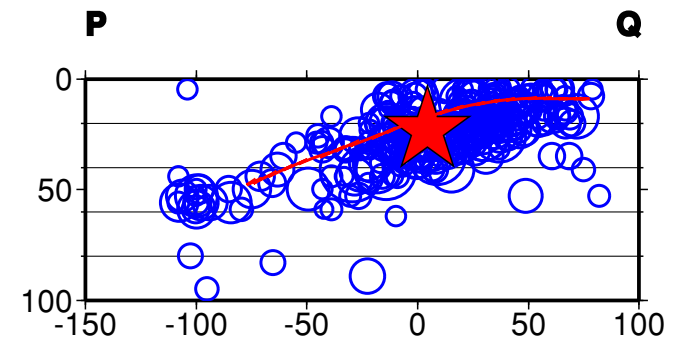

(b)

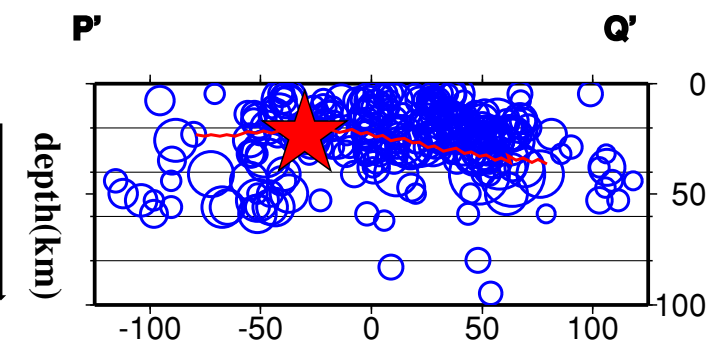

(c)

Fig. 1. (a). Spatial distribution of aftershocks of the 2003 Tokachi Oki earthquake in the study area. The inset map depicts regional tectonics in and around the study area (after Katsumata et al., 2003); NA: North American Plate, EU: Eurasian Plate, PA: the Pacific Plate, PH: the Philippine Sea Plate and KT: Kurile Trench. Arrows indicate the directions of plate motion. Open circles represent the epicenters of aftershocks; scale for magnitude being given on the right side of the map. Star represents the epicenter of the main shock, whose focal mechanism is plotted on the southwest corner of the map. (b). Vertical Section along $P Q(\mathrm{~N} 45 \mathrm{~W} \sim \mathrm{S} 45 \mathrm{E})$. The solid red line represent the plate boundary (after Katsumata et al., 2003) (c). Vertical section along $P^{\prime} Q^{\prime}(\mathrm{N} 45 \mathrm{E} \sim \mathrm{S} 45 \mathrm{~W})$. The solid red line represent the plate boundary (after Katsumata et al., 2003)

ing the best fit stress tensor: orientation (trend/plunge) of three principal stress axes and a parameter ' $R$ ' defining the relative size of the intermediate principal stress with respect to the maximum and minimum principal stresses. The best fit stress tensor is the one characterized by the minimum sum of misfit rotation ( $\square$ ) which is the sum of angle of rotation between each observed slip vector and calculated (model) slip vector.

The stress ratio defined as: $R=\left(\sigma_{1}-\sigma_{2}\right) /\left(\sigma_{1}-\sigma_{3}\right)$ determines the shape of the stress ellipse in a region (Mcken- zie, 1969; Gephart and Forsyth, 1984), where ' $\sigma_{1}$ ', ' $\sigma_{2}$ ' and ' $\sigma_{3}$ ' are the maximum, intermediate and minimum principal stresses respectively. Other workers (e.g., Angelier, 1979; Etchecopar et al., 1981; Ritz and Tabaoda, 1993), defined ' $R$ ' as ' $R$ ' $=\left(\sigma_{2}-\sigma_{3}\right) /\left(\sigma_{1}-\sigma_{3}\right)$. However, the inversion could not reveal absolute magnitudes of individual principal stress; the ' $R$ ' value determined by the inversion provides important insights on the relative sizes of principal stresses.

Referring to the value of ' $R$ ', three fold stress states viz. uniaxial, biaxial and triaxial can be categorized as ' $R$ ' ap- 


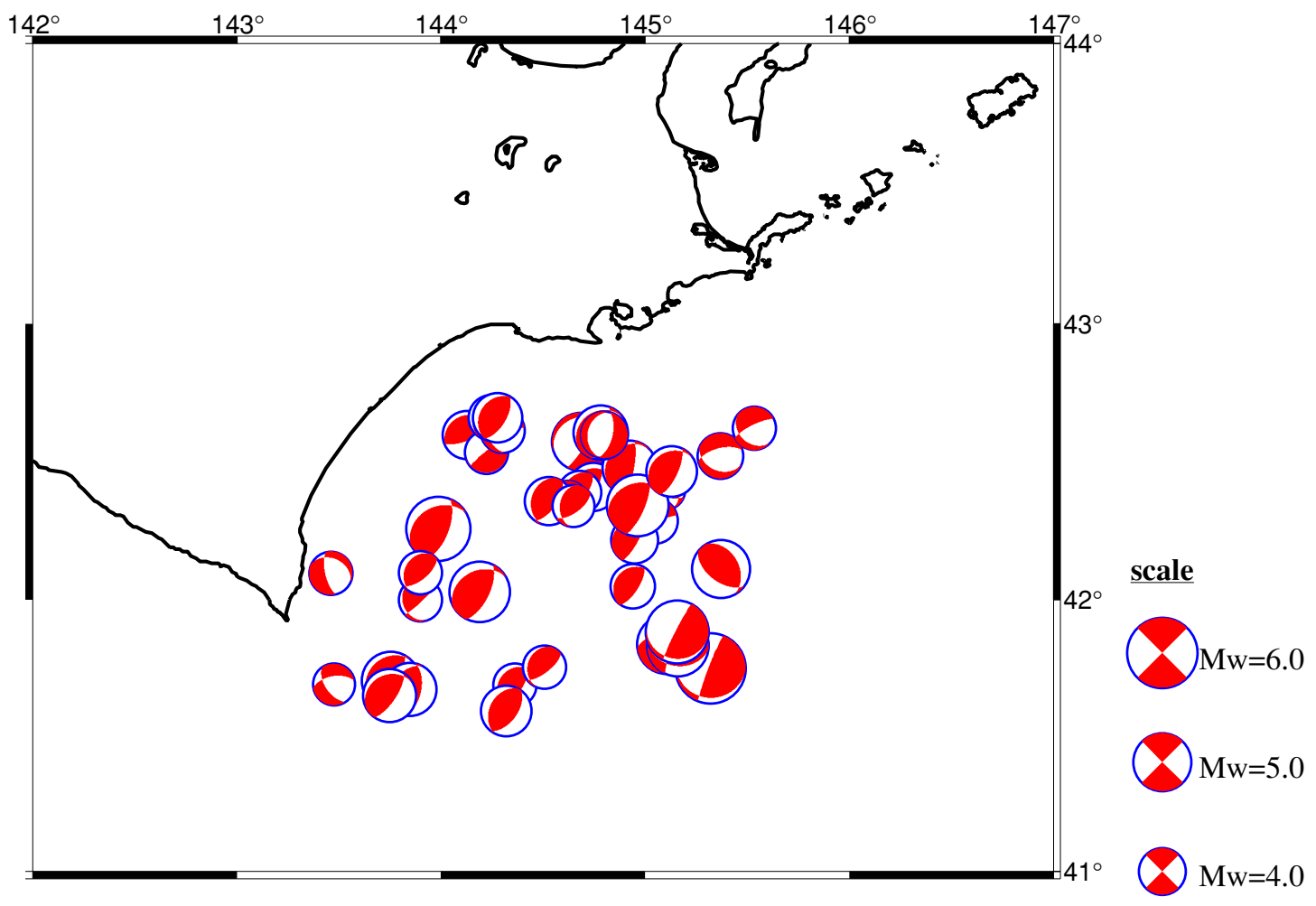

Fig. 2. Spatial distribution of focal mechanisms used in stress inversion for the preseismic condition. Total no. of data is 39 , characterized by higher variance reduction $(>75 \%)$ and shallow depth $(<40 \mathrm{~km})$.

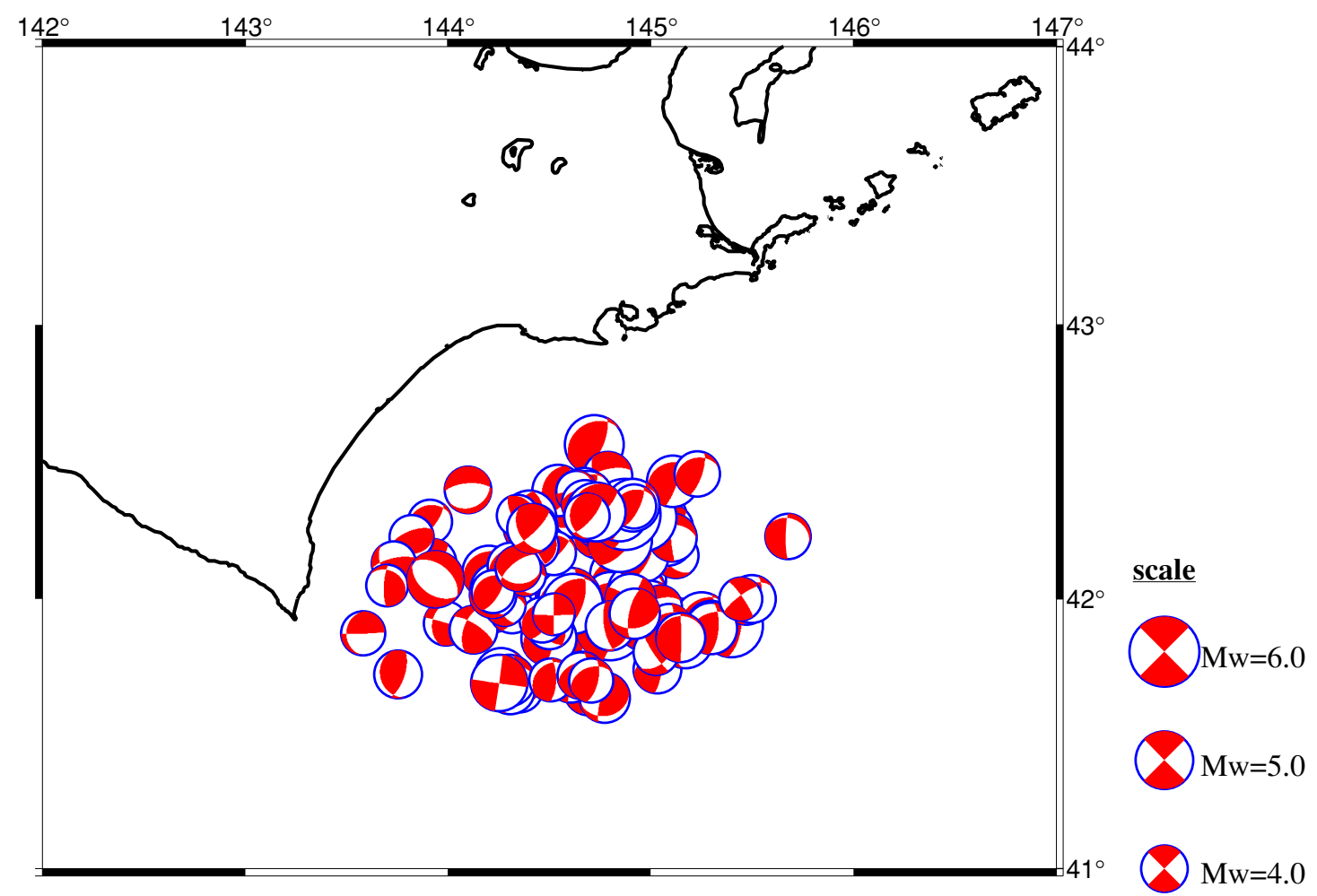

Fig. 3. Spatial distribution of aftershock focal mechanisms used in stress tensor inversion. Total no. of data is 120 characterized by higher variance reduction $(>75 \%)$ and shallow depth $(<40 \mathrm{~km})$.

proaches to '0' (or 1.0), 0.5 and midway between nearly uniaxial (compression: $0.85>R>1.0$ or extension: $0>R>0.15)$ and nearly biaxial $(0.45<R<0.55)$. As discussed by Ritz and Tabeoda (1993), the value of ' $R$ ' encompasses varieties of inferences on the state of stress in different stress regimes (tectonic loadings). For example, $R \rightarrow 1.0$ in an extensional regime is interpreted as a radial extension whereas the same value of ' $R$ ' in a strike- 
(a)

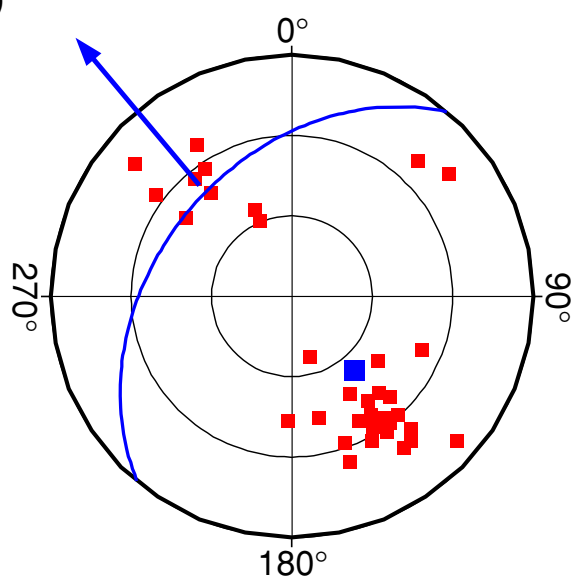

P-axes

(b)

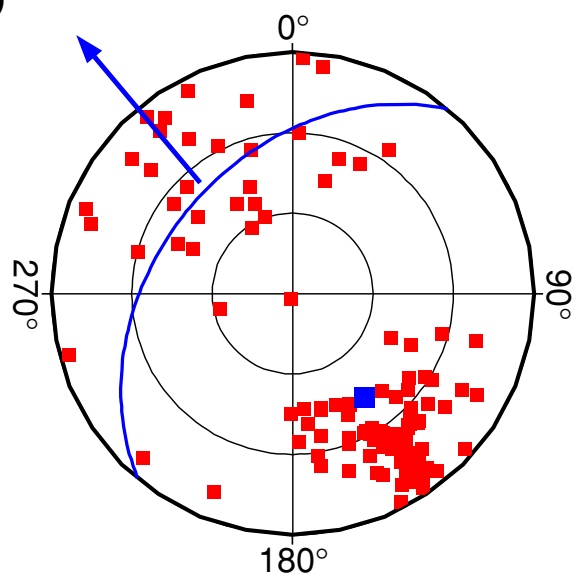

P-axes

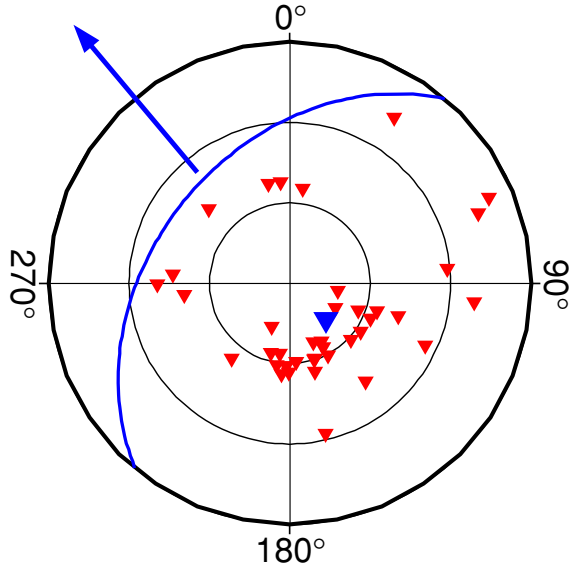

T-axes

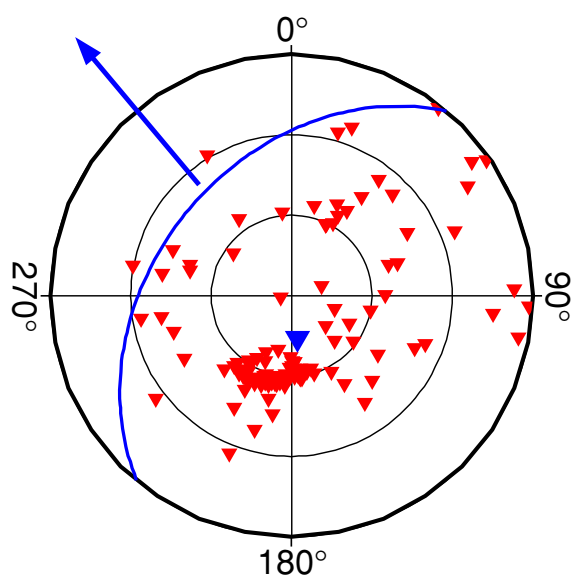

T-axes

Fig. 4. (a) Lower Hemispheric projection of $P$-and $T$-axes for the preseismic data set. Total number of data is 39 , the left panel is for the $P$-axis and the right panel is for the $T$-axis population. The mean orientation of $P$-axis (trend/plunge) is $140 / 54$ which is represented in the figure by the blue solid square. The mean orientation of $T$-axis is $135 / 71$ represented by the blue solid inverted triangle. The great circle represents the trace of downgoing Pacific slab (after Ozel and Moriya, 2003), and the arrow represents the dip direction of the downgoing slab. (b) Lower Hemispheric projection of $P$ and $T$-axes for the postseismic data set. Total number of data is 120 . The mean $P$-axis is $145 / 43$ and the mean $T$-axis is $172 / 74$.

slip regime (or a compressional regime) indicates a uniaxial compression. Similarly $R \rightarrow 0$ in an extensional regime is indicative of a uniaxial extension whereas the same value of ' $R$ ' in a compressional regime indicates a radial compression. Bellier and Zoback (1995) and Bellier et al. (1997) have provided detailed discussions on interpretation of $R$ values.

\section{Data}

In this study we used focal mechanism data published by National Research Institute for Earth Science and Disaster Prevention (NIED). Altogether 278 focal mechanism solutions of aftershocks during the period 2003/9/26 2004/4/4 were used to evaluate the stress tensor after the occurrence of Tokachi Oki main shock. To study the state of stress before the 2003 main shock about 300 data were retrieved from the NIED solutions that occurred in the period 1997/1/1 2003/9/20.
Figure 1 illustrates the distribution of aftershocks in the study area. The onset of aftershocks in the area exhibits a northeastward extension of seismcity after the occurrence of main shock (Fig. 1(a)). The depth section (Fig. 1(b) and (c)) indicate most of the events are confined at shallow depth $(<40 \mathrm{~km})$.

For the accuracy of stress tensor inversion, focal mechanism data with percentage of variance reduction $\geq 75$ were selected. Assuming the 2003 Tokachi Oki earthquake an interplate and considering the typical depth of downdip termination of the interplate earthquakes at subduction zones (Tichelaar and Ruff, 1993), only the aftershocks shallower than $40 \mathrm{~km}$ were selected for the inversion. Under these criteria only 39 out of 300 events were selected (Fig. 2) for the preseismic condition and only 120 out of 278 aftershocks were selected (Fig. 3) for the postseismic condition.

Orientations (trend/plunge) of $P$ and $T$ axes of the both data sets are plotted in a stereogram in Fig. 4 . The great 

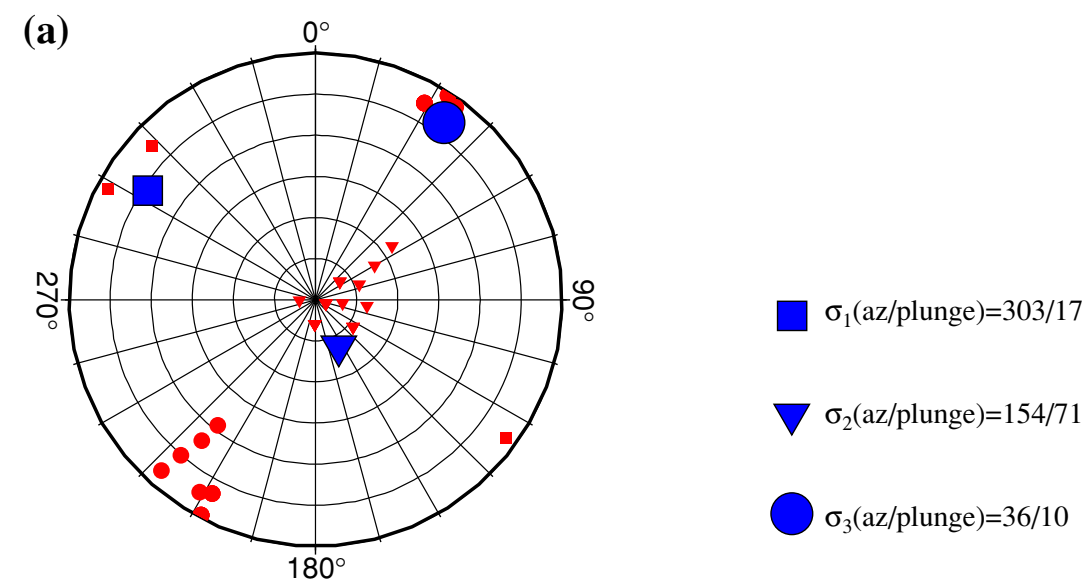

(b)

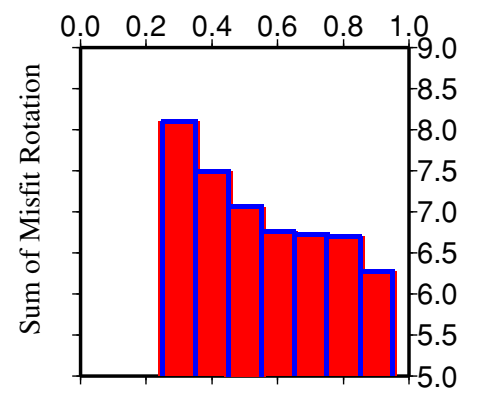

$\phi=-80.044$

$\mathrm{R}=0.9$

$\theta=6.273$

$\mathrm{N}=29$

R-Value

Fig. 5. Result of the stress tensor inversion in the area before the occurrence of the 2003 earthquake, (a) Lower hemispheric projection of the principal stress axes, calculated from the inversion. Small squares, inverted triangle and circles respectively represent the maximum, intermediate and minimum principal stress axes searched within $95 \%$ confidence limit of minimum sum of misfit rotation. $\sigma_{1}, \sigma_{2}$ and $\sigma_{3}$ represent the best fit principal stress axes with minimum sum of misfit rotation. (b) Histograms showing the $R$-values and associated sum of misfit rotation. 'Phi', ' $R$ ' and 'theta' are the angle made by the $\sigma_{2}$ axis with $\sigma_{1}$ axis in $\sigma_{1}-\sigma_{3}$ plane, the stress ratio and the minimum sum of misfit rotation for the best fit stress tensor. ' $N$ ' is the total number of stress models searched within $95 \%$ confidence limit of minimum sum of misfit rotation.

Table 1. A priori values used in stress inversion and result of the inversion.

\begin{tabular}{lccc}
\hline & Parameters & Preseismic condition & Postseismic condition \\
\hline A priori values & No. of data & 39 & 120 \\
& Primary stress axis & Mean $P$-axis $(140 / 54)$ & Mean $P$-axis $(145 / 43)$ \\
& Secondary stress axis & Mean $T$-axis $(135 / 71)$ & Mean $T$-axis $(172 / 74)$ \\
Result of stress inversion & $R$ & 0.9 & 0.2 \\
& Phi & -80.044 & 11.525 \\
& Theta & 6.273 & 8.019 \\
& $\sigma_{1}$ (trend/plunge) & $303 / 17$ & $307 / 8$ \\
& $\sigma_{2}$ (trend/plunge) & $154 / 71$ & $38 / 11$ \\
$\sigma_{3}$ (trend/plunge) & $36 / 10$ & $183 / 76$ \\
\hline
\end{tabular}

$R=$ Stress Ratio. Phi=rake of $\sigma_{2}$ on the plane perpendicular to $\sigma_{1}$. Theta=minimum sum of misfit rotation. $\sigma_{1}, \sigma_{2}$ and $\sigma_{3}$ are the principal stress axes.

circle in Fig. 4 represents the trace of the subducting Pacific Slab (adopted from Ozel and Moriya, 2003). The mean orientation of $P$-axis population before and after the 2003 main shock does not differ significantly $(P=140 / 54$ and $145 / 43$ respectively before and after the main shock). The preseismic mean $T$-axis (135/71) was however rotated southward (172/74) in the postseismic condition. The mean orientations of $P$ and $T$-axis populations were used as a priori values of the maximum and minimum principal stress axes during the stress inversion.

\section{Result}

Exact method of FMSI (Gephart, 1990) was used to invert the stress tensor from the available focal mechanism data. The mean values of $P$ - and $T$-axis (Fig. 4) were used as a priory values of the maximum and minimum principal stress axes which were chosen as the primary and secondary stress axes assuming an uncertainty of $60^{\circ}$ so that the best 


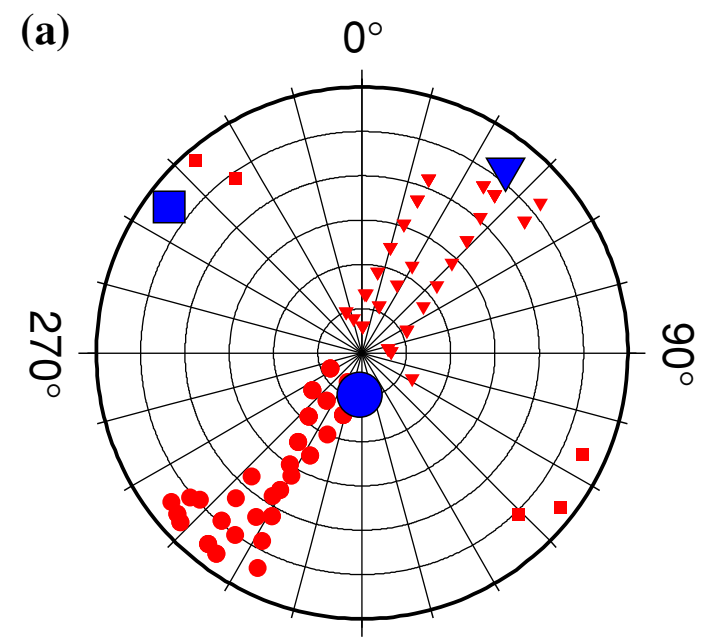

$180^{\circ}$

(b)

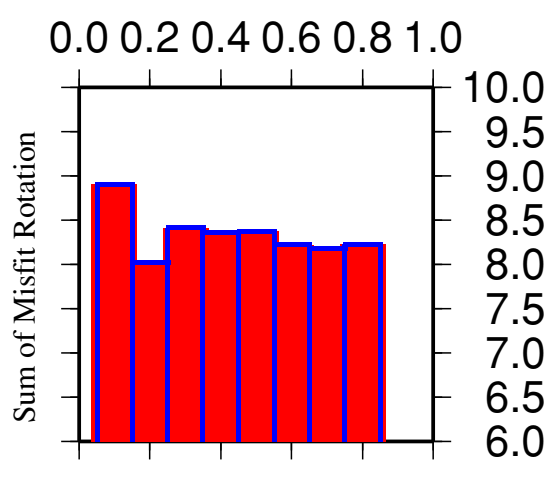

$\sigma_{1}($ az/plunge $)=307 / 8$

$\sigma_{2}($ az/plunge $)=38 / 11$

$\sigma_{3}(\mathrm{az} /$ plunge $)=183 / 76$

R-Value

Fig. 6. Result of stress tensor inversion in the study area after the occurrence of the 2003 earthquake. Symbols are the same as in Fig. 5.

fit stress tensor could be searched within a cone of $60^{\circ}$ in a grid space with $10^{\circ}$ grid spacing. The a priori values and result of stress inversion are presented in Table 1 . The uncertainties of $60^{\circ}$ for the a priori values were chosen because the mean $P$ and $T$ orientations are highly variable from the dip direction of the subducting Pacific Slab (Fig. 4). From a number of stress models tested in the inversion, those falling within $95 \%$ confidence limit of minimum sum of misfit rotation were plotted in the stereogram (Figs. 5 and 6).

The $95 \%$ confidence limit of minimum sum of misfit rotation was calculated by using the following formula modified by Gephart and Forsyth (1984) from Parker and McNutt (1980).

$\sum_{95}=\left[\left(1.96(\pi / 2-1)^{1 / 2} n^{1 / 2}+n\right) /(n-4)\right] \theta$; where, ' $n$ ' is the number of observation and ' $\theta$ ' is the minimum sum of misfit rotation.

The minimum sum of misfit rotation for the two data sets are far below the threshold value of $20^{\circ}$ as discussed by Bellier et al. (1997) indicating fairly reliable inversion result. The number of stress models within $95 \%$ confidence limit are comparable for the two data sets $(N=29$ for preseismic data set and $N=56$ for the postseismic data set). Histograms of ' $R$ ' values for the stress models within $95 \%$ confidence limit of minimum sum of misfit rotation are plotted against the misfit rotation of stress models in Figs. 5 and 6.

For the preseismic condition $R=0.9$ and the orientations of the stress axes $\left(\sigma_{1}=303 / 17, \sigma_{2}=154 / 71\right.$ and $\sigma_{3}=36 / 10$ ) indicates nearly uniaxial compression in the strike-slip regime (Ritz and Taboda, 1993). The state of stress for this data set is illustrated in Fig. 7(a). On the other hand, for the postseismic condition the inversion result $\left(R=0.2, \sigma_{1}=307 / 8, \sigma_{2}=38 / 11\right.$ and $\left.\sigma_{3}=183 / 76\right)$ revealed nearly radial compression in compressional regime (Fig. 7(b)). The inversion result shows that the value of ' $R$ ' and the type of vertical principal stresses are significantly changed by the 2003 Tokachi Oki earthquake in the study area; however the orientation of the maximum principal stress axis was not affected significantly.

\section{Discussion and Conclusion}

The Mw 7.9 interplate event of 2003 broke the seismic quiescence in the Tokachi Oki area and augmented the seismicity in the area by more than 11 times as the preseimic events for more than 6 years period $(N=300)$ is nearly the same as the postseismic events for about 6 months $(N=277)$. Occurrence of the 2003 main event after an interseismic period of more than $50 \mathrm{yr}$ (since the previous Tokachi Oki event in the same source region is dated back to 1952), suggests that the mechanical coupling of this seis- 


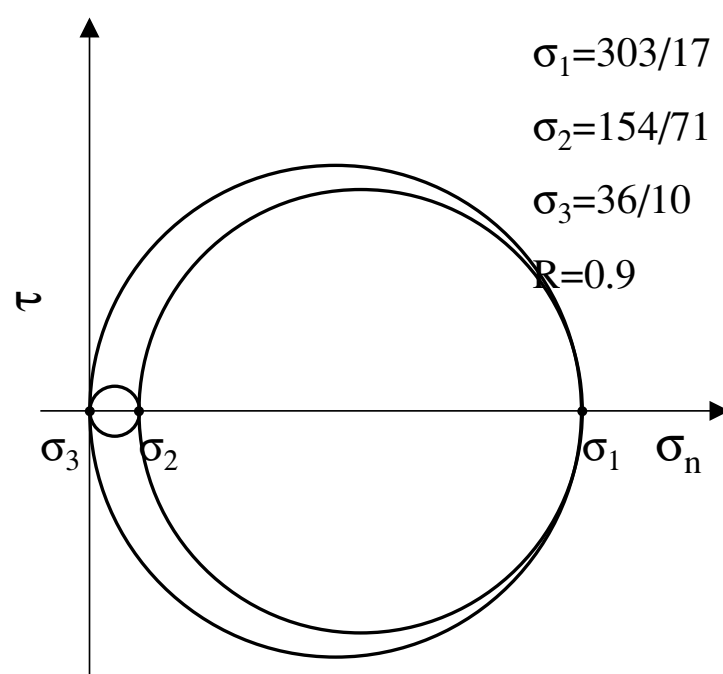

(a)

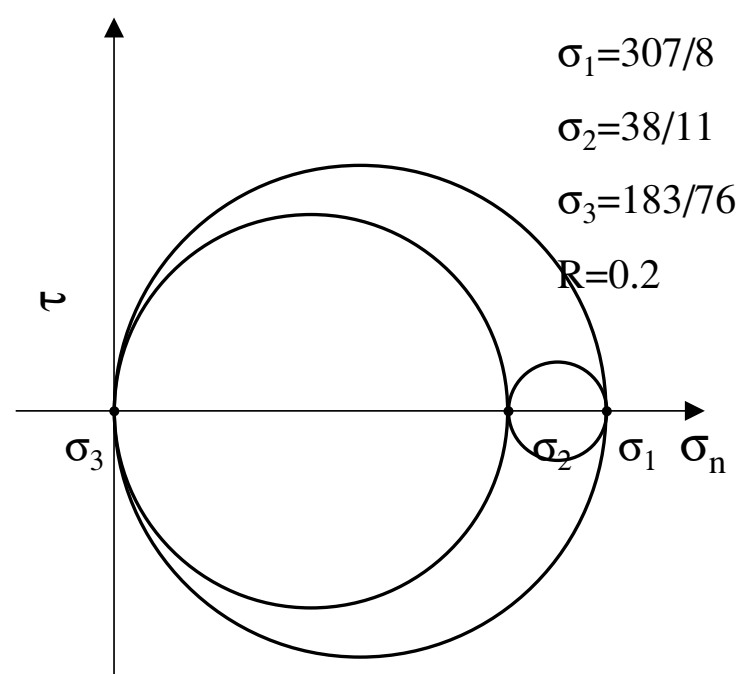

(b)

Fig. 7. Mohr diagrams illustrating the state of stress in the study area (a) preseismic and (b) postseismic condition. $\sigma_{1}, \sigma_{2}$, and $\sigma_{3}$ represent the maximum, intermediate and the minimum principal stress respectively. The Mohr circles are plotted without scale based on $R$ values.

$\mathrm{P}$

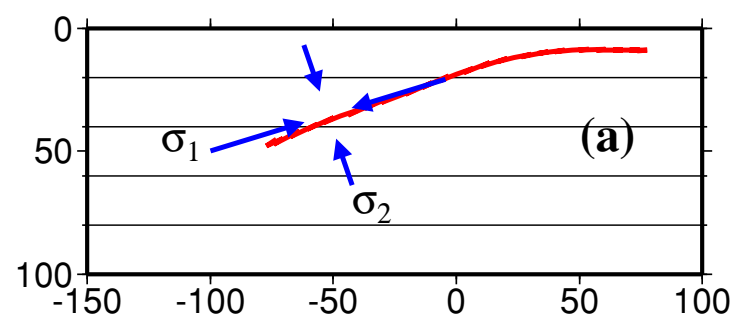

$\mathrm{P}$

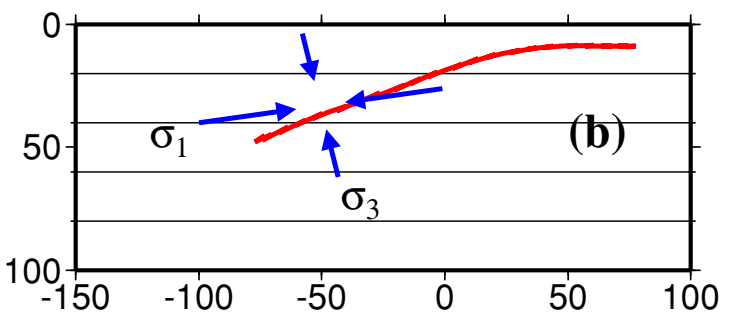

Fig. 8. Orientation of the principal stress axes in depth section with respect to the downgoing Pacific slab (a) preseismic and (b) postseismic condition. The depth section is adopted from Fig. 1(b) without any exaggeration in scale.

mogenic zone was not weak.

Orientations of $P$ - and $T$-axis revealed that the $P$-axes are preferentially clustered in SE and NW direction (normal to the Trench Axis) with comparatively shallow dip both in pre-seismic and post-seismic conditions, whereas the $T$ axes show steep plunges in SW and NE direction (Fig. 4). The mean orientation (trend/plunge) of $P$-axis is found as $140 / 54$ and 145/43 before and after the occurrence of the main shock whereas the Pacific slab dips at 320/40. On the other hand the mean orientation of $T$-axis is 135/71 and 172/74 for the two data sets. Mean $T$-axis exhibits a steep angle with the dip direction of the Pacific slab.

Stress tensor inversion of the focal mechanism data revealed that the orientation of the maximum principal stress before and after the main shock remained nearly unchanged (307/8 after the main shock and 303/17 before the main shock, Figs. 5 and 6) as compared to the intermediate and minimum principal stress axes. The orientation of the principal stress axes with respect to the plate boundary in the study area is illustrated in Fig. 8, the boundary of Pacific slab being adopted from Katsumata et al. (2003). The maximum principal stress before the main shock is nearly parallel to the subducting Pacific slab which was disturbed by the release of strain energy during the 2003 Tokachi Oki earthquake and became more horizontal (Fig. 8). Nevertheless, the dip directions of the maximum principal stress axes remain nearly unchanged and are nearly the same as the dip direction of the downgoing Pacific slab (Fig. 9), indicating the dominating stress before and after the 2003 earthquake was supplied by the tectonic stress driving the Pacific slab beneath the Kurile Trench.

However coseismic stress changes during an earthquake in an area are negligible with respect to the preexisting shear stress, this small perturbation in stress field is sufficient to enhance the seismicity in a seismogenic zone (Scholz, 2002). Yagi (2004) calculated the static stress drop in the area as much as $10 \mathrm{MPa}$ in the main asperity region along with the maximum increase of $3 \mathrm{MPa}$ in the area surrounding the main asperities of the 2003 event. This slight modification in shear stress in the area should have affected the preexisting principal stress directions and changed the stress ellipsoid in the study area.

Figure 7 represents the stress tensors in the study area for the two data sets exhibiting the temporal change in state of stress, where the Mohr circles are plotted without scale based on ' $R$ ' values. Figure 7 shows that the state of stress 


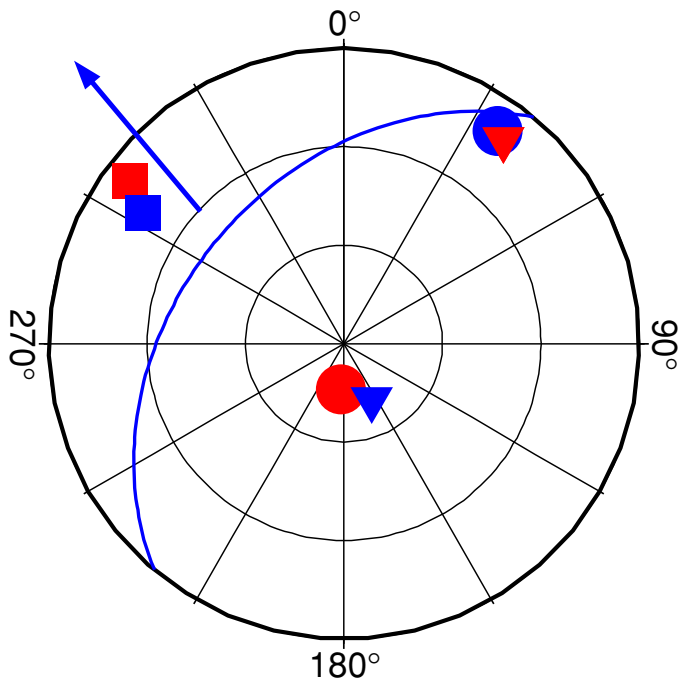

Fig. 9. Comparison of principal stress axes along with the dip direction of the Pacific slab. The red square, inverted triangle and circle represent the maximum, intermediate and minimum principal stress after the occurrence of the 2003 event whereas the blue ones represent those before the occurrence of the 2003 event. The great circle represents the lower hemispheric projection of the trace of the Pacific slab and the arrow line represents the dip direction of the slab.

was changed significantly in the aftershock area after the occurrence of the main shock of 2003. Before the occurrence of the main shock the study area is characterized by the strike-slip regime such that the intermediate principal stress is nearly vertical. Value of $R$ is 0.9 for this case, which implies nearly a uniaxial compression normal to the trench axis. The preseismic uniaxial compression state of stress was changed to a transition from transpressional to a radial compression in the compressional regime ( $\sigma_{3}$ vertical and $R=0.2$ ).

Fluids released from metamorphic reactions (typically dehydration) in subduction zones (Peacock, 1990; Vroljik, 1990) and by lithification (typically compaction, e.g., Moore, 1989) might be entrapped in the fault zones by hydraulically sealing the fault zone by mineral precipitations (e.g. Blanpied et al., 1992; Sleep and Blanpied, 1992; Byerlee, 1993) such that the pore pressure in the fault zone may be elevated from the hydrostatic condition (but still less than lithostatic) and might further weaken the fault zone (Rice, 1992). The 2003 Tokachi Oki earthquake might have broken such a relatively weak fault zone resulted from elevated pore pressure. The postseismic stress state, where the minimum principal stress became nearly vertical (Figs. 7(b) and 8(b)) serves as a favorable environment to squeeze the excess fluid at the fault zone because of a radial compression $(R=0.2)$ in a compressional regime.

Acknowledgments. One of the authors Mr. Subesh Ghimire would like to acknowledge the Ministry of Education, Science and Culture (MONBUKAGAKUSHO) for granting scholarship to pursue his study in Japan. The authors would like to thank Professors T. Moriya, T. Sasatani and Y. Tanioka for fruitful discussions and invaluable comments and suggestions during the preparation of this manuscript. Authors are equally indebted to Prof. M. Kosugo of Hirisaki University and Dr. S. Matsumura of NIED for their comments which were very fruitful to improve the manuscript.
The stress inversion was carried out by compiling the FORTRAN codes from Gephart (1990).

\section{References}

Astiz, L., T. Lay, and H. Kanamori, Large intermediate depth earthquakes and the subduction process, Phys. Earth Planet. Int., 53, 80-166, 1988.

Bellier, O. S. and M. L. Zoback, Recent state of stress change in the Walker Lane zone, western Basin and Range Province, United States, Tectonics, 14, 3, 564-593, 1995.

Bellier, O., S. Over, A. Poisson, and J. Andrieux, Recent temporal change in the stress state and modern stress field along the North Anatolian Fault Zone (Turkey), Geophys. J. Int., 131, 61-86, 1997.

Blanpied, M. L., D. A. Locksner, and J. D. Byerlee, An earthquake mechanism based on rapid sealing of faults, Nature, 358, 574-576, 1992.

Byerlee, J., Model for episodic flow of high pressure water in fault zones before earthquakes, Geology, 21, 303-306, 1993.

Carey-Gailhardis, E. and J. L. Mercier, A numerical method for determining the state of stress using focal mechanisms of earthquake populations: Application to Tibetan teliseisms and microseismicity of Southern Peru, Earth Planet. Sci. Lett., 82, 165-179, 1987.

DeMets, C., R. G. Gordon, D. F. Argus, and S. Stein, Current plate motions, Geophys. J. Int., 101, 425-478, 1990.

Etchecopar, A., G. Vasseur, and J. L. Mercier, An inverse problem in microtectonics for the determination stress tensors from fault striation analysis, J. Struct. Geolog., 3, 51-65, 1981.

Frepoli, A. and A. Amato, Spatial variation in stress in Peninsular Italy and Sicily from background seismicity, Tectonophysics, 317, 109-124, 2000 .

Gephart, J. W., FMSI: A FORTRAN program for inverting fault/ slickenside and earthquake focal mechanism data to obtain the regional stress tensor, Computers and Geosciences, 16, 7, 953-989, 1990.

Gephart, J. W. and D. W. Forsyth, An improved method for determining the regional stress tensor using earthquake focal mechanism data: application to the San Fernando Earthquake sequence, J. Geophys. Res., 89, 9305-9320, 1984.

Hasegawa, A., N. Umino, and A. Takagi, Double-planed structure of the deep seismic zone in the Northeastern Japan arc, Tectonophysics, 47, 43-58, 1978.

Hasegawa, A., N. Umino, A. Takagi, S. Suzuki, Y. Motaya, S. Kameya, K. Tanaka, and Y. Sawada, Spatial distribution of earthquakes beneath Hokkaido and northern Honshu, Japan, J. Seism. Soc. Jpn. Ser. 2, 36, 129-150, 1983 (in Japanese).

Isacks, B. and P. Molnar, Distribution of stresses in the descending lithosphere from a global survey of focal mechanisms solutions of mantle earthquakes, Rev. Geophys. Space Phys., 9, 103-174, 1971.

Kanamori, H., Focal mechanism of the Tokachi Oki earthquake of May 16, 1968: Contortion of the lithosphere at a junction of two trenches, Tectonophysics, 12, 1-13, 1971a.

Kanamori, H., Seismological evidence for lithospheric normal faulting: the Sanriku earthquake of 1933, Phys. Earth Planet. Inter., 4, 289-300, $1971 b$.

Katsumata, K., N. Wada, and M. Kasahara, Newly imaged shape of the deep seismic zone within the subducting Pacific plate beneath the Hokkaido corner. Japan-Kurile arc-arc junction, J. Geophys. Res., 108, 2003.

Kiratzi, A. A., Stress tensor inversions along the westernmost North Anatolian Fault Zone and continuation into the North Aegean Sea, Geophys. J. Int., 151, 360-376, 2002.

Kosuga, M., T. Sato, A. Hasegawa, T. Matsuzawa, S. Suzuki, and Y. Motoya, Spatial distribution of intermediate-depth earthquakes with horizontal or vertical nodal planes beneath northeastern Japan, Phys. Earth Planet. Int., 93, 63-89, 1996.

Kubo, A. and E. Fukuyama, Stress field along the Ryuku Arc and Okinawa Trough inferred from moment tensors of shallow earthquakes, Earth. Planet. Sci. Lett., 210, 305-316, 2003.

Magee, M. E. and M. D. Zoback, Evidence for a weak interplate thrust fault along the northern Japan subduction zone and implications for the mechanics of thrust faulting and fluid expulsion, Geology, 21, 809-812, 1993.

McKenzie, D. P., The relation between fault plane solutions for earthquakes and the directions of the principal stresses, Bull. Seism. Soc. Am., 59, 591-601, 1969.

Michael, A. J., Determination of stress from slip data: Faults and folds, $J$. Geophys. Res., 89, 11,517-11,526, 1984.

Michael, A. J., Use of focal mechanisms to determine stress: A control 
study, J. Geophys. Res., 92, 357-368, 1987.

Moore, J. C., Tectonics and hydrogeology of accretionary prisms: role of the decollment zone, J. Structural Geology, 11, 95-106, 1989.

Moriya, T., Collision of forearcs and overlapped deep seismic zone in the transition zone between the northern Honshu and Kurile arcs, J. Phys. Earth, 34(suppl.), S175-S192, 1986.

Ozel, N. and T. Moriya, Different stress directions in the aftershock focal mechanisms of the Kushiri-Oki earthquake of Jan. 15, 1993, SE Hokkaido, Japan, and horizontal rupture in the double seismic zone, Tectonophysics, 313, 307-327, 1999.

Ozel, N. and T. Moriya, Focal mechanism of Intermediate-depth earthquakes beneath southeastern Hokkaido, Japan, implications of the double seismic zone, Pure and Applied Geophysics, 160, 2279-2299, 2003.

Parker, R. L. and M. K. McNutt, Statistics for the one norm misfit measure, J. Geophys. Res., 85, 4429-4430, 1980.

Peacock, S. M., Fluid processes in subduction zones, Science, 248, 329337, 1990.

Rice, J. R., Fault stress states, pore pressure distribution and the weakness of the San Andreas Fault, in Fault Mechanics and Transport Properties of Rock, edited by B. Evans and T. F. Wong, pp. 475-503, London Academic Press, 1992.

Ritz, J. F. and A. Taboada, Revolution stress ellipsoids in brittle tectonics resulting from uncritical use of inverse methods, Bull. Soc. Geol. France, 164, 519-533, 1993.

Scholz, C. H., The Mechanics of Earthquakes and Faulting, Second Edition, Cambridge University Press, 471 pp., 2002.

Schwartz, S. C. and L. J. Ruff, The 1968 Tokachi Oki and the 1969 Kurile islands earthquakes: variability in the rupture processes, J. Geophys. Res., 90, 8613-8626, 1985.

Seno, T., "Northern Honshu microplate" hypothesis and tectonics in the surrounding region. When did the plate boundary jump from central Honshu to the eastern margin of Japan sea?, J. Geod. Soc. Jpn., 31, 106-123, 1985.

Sleep, N. H. and M. L. Blanpied, Creep, compaction and the weak rheology of major faults, Nature, 359, 687-692, 1992.

Suzuki, S. and M. Kasahara, Unbending and horizontal fracture of the subducting Pacific plate, as evidenced by the 1993 Kushiro-Oki and 1981 and 1987 intermediate-depth earthquakes in Hokkaido, Phys. Earth Planet. Int., 93, 91-104, 1996.

Suzuki, S., T. Sasatani, and Y. Motoya, Double seismic zone beneath the middle of Hokkaido, Japan, in the southwestern side of the Kurile arc, Tectonophysics, 96, 59-76, 1983.

Tichelaar, B. W. and L. J. Ruff, Depth of seismic coupling along subduction zones, J. Geophys. Res., 98, 2017-2037, 1993.

Tsumura, N., H. Ikawa, T. Ikawa, M. Shinohara, T. Ito, K. Arita, T. Moriya, G. Kimura, and T. Ikawa, Delamination-wedge structure beneath the Hidaka collision zone, central Hokkaido, Japan, inferred from seismic refraction profiling, Geophy. Res. Lett., 26, 1057-1060, 1999.

Vroljik, P., On the mechanical role of smectite in subduction zones, Geology, 18, 703-707, 1990.

Yagi, Y., Source rupture process of the 2003 Tokachi-Oki earthquake determined by joint inversion of teleseismic body wave and strong ground motion data, Earth Planets Space, 56, 311-316, 2004.

Yoshii, T., A detailed cross section of the deep seismic zone beneath northeastern Honshu, Japan, Tectonophysics, 55, 349-360, 1979.

S. Ghimire (e-mail: subesh@eos.hokudai.ac.jp), K. Katsumata, and M. Kasahara 